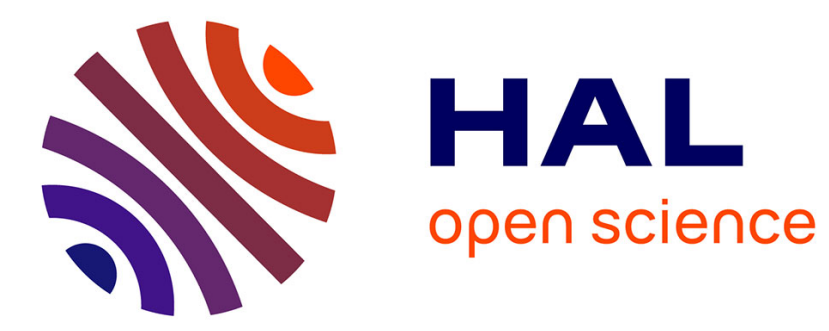

\title{
Melatonin Affects the Temporal Pattern of Vocal Signatures in Birds
}

Sébastien Derégnaucourt, Sigal Saar, Manfred Gahr

\section{To cite this version:}

Sébastien Derégnaucourt, Sigal Saar, Manfred Gahr. Melatonin Affects the Temporal Pattern of Vocal Signatures in Birds. Journal of Pineal Research, 2012, 53 (3), pp.245-258. 10.1111/j.1600079X.2012.00993.x . hal-01478498

\section{HAL Id: hal-01478498 \\ https://hal.parisnanterre.fr/hal-01478498}

Submitted on 22 Nov 2017

HAL is a multi-disciplinary open access archive for the deposit and dissemination of scientific research documents, whether they are published or not. The documents may come from teaching and research institutions in France or abroad, or from public or private research centers.
L'archive ouverte pluridisciplinaire HAL, est destinée au dépôt et à la diffusion de documents scientifiques de niveau recherche, publiés ou non, émanant des établissements d'enseignement et de recherche français ou étrangers, des laboratoires publics ou privés. 


\section{Melatonin affects the temporal pattern of vocal signatures in birds}

Sébastien Derégnaucourt ${ }^{1 *}$, Sigal Saar ${ }^{2}$ and Manfred Gahr ${ }^{1}$

${ }^{1}$ Department of Behavioural Neurobiology, Max Planck Institute for Ornithology, D82319 Seewiesen, Germany.

${ }^{2}$ Department of Biology, City College of New York, City University of New York, New York, NY, USA.

* To whom correspondence should be addressed:

Laboratoire d'Éthologie et Cognition Comparées, Université Paris Ouest Nanterre La

Défense, 200 avenue de la République, F92001 Nanterre Cedex, France. Phone: +33-1-

40-97-74-77. Fax: +33-1-40-97-74-74. Email: sebastien.deregnaucourt@u-paris10.fr

Running title: melatonin and birdsong

Keywords: melatonin, pinealectomy, birdsong, vocalization, timing, motor control, learning, Zebra finch, Japanese quail 


\section{Abstract}

In humans and other animals, melatonin is involved in the control of circadian biological rhythms. Here we show that melatonin affects the temporal pattern of behavioural sequences in a non-circadian manner. The zebra finch (Taeniopygia guttata) song and the crow of the Japanese quail (Coturnix japonica) are courtship vocalizations composed of a stereotyped sequence of syllables. The zebra finch song is learned from conspecifics during infancy whereas the Japanese quail crow develops normally without auditory input. We recorded and analyzed the complete vocal activity of adult birds of both species kept in social isolation for several weeks. In both species, we observed a shortening of signal duration following the transfer from a light-dark (LD) cycle to constant light (LL), a condition known to abolish melatonin production and to disrupt circadian rhythmicity. This effect was reversible since signal duration increased when the photoperiod was returned to the previous LD schedule. We then tested whether this effect was directly related to melatonin by removal of the pineal gland, which is the main production site of circulating melatonin. A shortening of the song duration was observed following pinealectomy in LD. Likewise, melatonin treatment induced changes in the temporal structure of the song. In a song learning experiment, young pinealectomized finches and young finches raised in LL failed to copy the temporal pattern of their tutor's song. Taken together, these results suggest that melatonin is involved in the control of motor timing of non-circadian behavioural sequences through an evolutionary conserved neuroendocrine pathway. 


\section{Introduction}

Many organisms exhibit neural systems that produce sequenced behaviour with high temporal precision [1-4]. One neural system that has received particular interest is the song control system: a network of neural circuits that controls singing behaviour in oscine songbirds [5]. The song of the zebra finch (Taeniopygia guttata) exhibits several characteristics that make it an ideal model system for understanding temporal sequence production and learning. The song is learned during a sensitive period, is highly stereotyped and has a hierarchical temporal structure spanning multiple timescales [6]. Adult male finches produce a $0.5-1.5$-s song motif that is repeated several times during a bout of singing [6]. The motif is composed of few syllable types uttered in a fixed order. Syllable types often contain a combination of different sounds usually called notes [7]. Order and duration of syllable types as well as duration of intersyllabic gaps are highly stereotyped.

Behavioural and physiological experiments have been carried out to decipher the motor code for song production [8-12]. In many oscines, the learned song structure remains stable after reaching adulthood. However, brain lesions [13] and disruption of auditory feedback [14-16] induce significant vocal changes in adult birds. Recently, Long and Fee [17] showed that experimental selective cooling of the HVC (a telencephalic song nucleus) stretches the temporal pattern of the song while leaving other acoustic features such as pitch unchanged.

Similarly, an influence of melatonin on the temporal organization of the song has been observed [18]. Melatonin is a hormone produced during darkness, and involved in the control of circadian rhythmicity [19]. In many oscines [20,21] including the zebra 
finch $[18,23]$, brain structures associated with song control express melatonin receptors. Administration of a melatonin receptor antagonist during the night decreases song length the following day [18].

Here we take one step towards understanding the role of melatonin on birdsong. In a suite of experiments, we show that (a) changes of the temporal organization of the song can be induced reversibly following a period of constant light (LL) known to abolish melatonin production, (b) using the same treatment, similar changes can be induced in the vocal signature of a vocal non learner species, the Japanese quail (Coturnix japonica, galliform), (c) pinealectomy and melatonin treatment affect the temporal pattern of the zebra finch song and (d) abolishment of melatonin using either a LL treatment or pinealectomy affects song learning in finches. Taken together, these observations suggest that melatonin plays a role in the control of the temporal pattern of vocal signatures in birds.

\section{Material and Methods}

\section{Subjects and housing}

All experimental procedures were approved by the governmental authorities of Upper Bavaria.

The zebra finches used were young and adult (200-400 days post hatching: dph) males from our breeding colony at Seewiesen. Before the experiments, adult male finches were transferred from aviaries to individual sound boxes where they were in complete social and acoustic isolation. Breeding pairs were raised in a single cage (LD 12:12). Two 
weeks after hatching, the chicks were isolated with their mother in a room (LD 12:12), in complete isolation from males, to avoid any imprinting on adult songs. On day 30 , young males were isolated in individual soundproof boxes (LD 12:12).

The ten male Japanese quails used were purchased from a local supplier when they were 3 weeks old. At their arrival in the laboratory, each quail was socially and acoustically isolated in a soundproof box (LD 12:12 and then LD 14:10). Quails were maintained in LD 14:10 for an additional month after they reached sexual maturity and started crowing regularly.

\section{Constant light (LL)}

In most diurnal species, exposure to constant bright light leads to an arrhythmia of different biological cycles, and suppresses the daily melatonin production in birds [24]. Therefore we predicted that maintaining a bird in LL should affect song structure if effects of melatonin on song were pervasive.

We used both adult male finches and quails. Eight adult finches were used for this experiment. After 2 weeks in LD 12:12, they were transferred in LL for 2 weeks. The photoperiod was then switched to LD 12:12 for an additional 2 weeks (Fig. 1A). Light intensity $(\sim 1,000$ lux in the center of the cage) was similar to those of the light phase of the baseline period before the transfer in LL. One bird was also raised under dim ( 0.1 lux $)$ LL conditions. Ten adult males Japanese quails raised in LD 14:10 were then transferred 
to LL for 2 weeks. Then, the photoperiod was switched to LD 14:10 for an additional month. Finally, they were transferred again in LL for 2 weeks (Fig. 1B).

\section{Pinealectomy}

Ten adult male zebra finches were acclimatized to the sound boxes for one month to record baseline song activity. They were then surgically pinealectomized (PINX, n= 5) or SHAM operated $(n=5)$. Birds were anesthetized with isofluorane, and the head was secured in a stereotaxic apparatus. A scalpel was used to make a longitudinal incision in the scalp and the exposed skullcap was removed using forceps. The dura was then incised and retracted and the exposed pineal gland was removed (PINX group) or left intact (SHAM group). The skullcap was then replaced and the scalp sutured. Birds were allowed to recover in their cages, and were isolated for another month (Fig. 1C). During the whole experiment, photoperiod was maintained at LD 12:12.

To check the success of pinealectomy, blood was collected at the end of the experiment, in the middle of the night, using a small beam of light to detect the alar vein. Blood sample were collected from the alar vein within 5 min of capture, kept on ice until centrifugation and then stored at $-80^{\circ} \mathrm{C}$. The concentration of plasma levels of melatonin were determined by direct radioimmunoassay (RIA) following Goymann et al. [25]. Levels of melatonin were very low (undetectable) for all PINX birds and in the normal range for control and SHAM finches (394 $\pm 37 \mathrm{pg} / \mathrm{ml}$ [190-662]). 


\section{Melatonin cream}

We tested the influence of melatonin administration on song using a melatonin cream [25]. This method allows the delivery of a defined amount of melatonin at a specific point in time. We applied $50 \mu \mathrm{l}$ of cream (melatonin dissolved in Eucerin cream, $0.4 \mathrm{mg} / \mathrm{g}$ ) with a syringe to the area of naked skin between the dorsal feather ridge, the wing, and the neck. The treatment was done just before lights off in the soundproof chamber.

\section{Directed/undirected song}

Song production is affected by social cues in zebra finches; when singing to females (directed song), they sing faster [6] and produce syllables with subtle but significantly less spectral variability [26] than when they sing alone (undirected song). On the last day of LL, a female was introduced into each male's cage for 3-4 hours in order to record directed song. This same procedure was applied for a single day before the experiment ended, when the bird was in LD 12:12.

\section{Song learning experiments}

We used a one-by-one tutoring schedule (one young with an adult) which seems the best approach to get a close match to the tutor song [27].

Constant light. From dph 43-100, young males $(\mathrm{n}=5)$ were exposed to an adult male tutor. On day 43, the photoperiod was switched from LD 12:12 to LL. On day 100, the adult male was removed and isolated in a sound box. Both birds were transferred to LD 
12:12 for an additional 2 weeks. Control birds were also exposed to an adult male tutor from dph 43-100 but they were raised in LD12:12 during the whole experiment (Fig. 1D).

Pinealectomy. On day $38-42$, juvenile males $(\mathrm{n}=12)$ were either pinealectomized $(\mathrm{n}=6)$ or sham-pinealectomized $(\mathrm{n}=6)$. On day 43 , an adult male was introduced in the sound box (LD 12:12). On day 100, the adult male was removed, and the young male was kept alone for an additional 2 weeks (Fig. 1E). In order to prevent the adult male from pecking at the scars on the skull of the sham or pinealectomized bird, the young bird was separated from the adult behind a wire lattice in an adjacent cage.

\section{Recording and analysis of vocal activity}

Online detection of the production of vocalizations. During the entire experiment, vocal activity of each individual bird was continuously recorded using the Sound Analysis Pro software (SAP 2.0, http://ofer.sci.ccny.cuny.edu/html/sound_analysis.html, [28]. The program was run on a PC equipped with an Edirol UA1000 sound card (16 bits, sampling frequency: $44.1 \mathrm{kHz}$ ), connected to multidirectional Earthworks TC20 microphones (one per sound box) placed above the cage. Each bird's vocalizations were monitored continuously. To avoid recordings of cage noises, we adjusted the settings of the software (amplitude and duration thresholds) so that only songs (zebra finch) or crows (Japanese quail) would be automatically identified and recorded.

Offline analysis of songs and crows. Vocalizations were subsequently analyzed offline using the batch module of SAP. The software then performed multitaper spectral analysis to compute spectral derivatives and acoustic features as documented in the Sound 
Analysis Pro (SAP) user manual. Subsequent analysis was based on the six acoustic features that were computed in each spectral frame: amplitude, pitch, Wiener entropy, FM, continuity and goodness of pitch [29]. We adjusted amplitude and Wiener entropy thresholds so that each song or crow would be segmented in syllables. For each syllable, different acoustic features based on the main ones mentioned above (see Table 1 for a complete list) were automatically calculated by the software, and results (both for raw data and segmented sounds) were stored in mySQL 4.0 tables (http://mySQL.com; one daily table per bird). Final stages of analysis were performed with Microsoft Excel and Matlab (The Mathworks, Natick, MA).

Adult song. We used two methods to estimate changes in motif duration during the experiment.

First method: We randomly selected 30 motifs per bird for each sampling time. Motif onsets and offset times were determined using a threshold crossing of song power, in which the threshold was held constant for all sampling time within each bird. From the onset and offset times, the motif duration was calculated.

We also estimated sound density and silence gaps. We define a 'syllable' as a continuous sound element, surrounded by silent intervals. We defined sound density as the sum of all syllable durations within a motif, and silence gaps as the sum of all silence durations within a motif. 
Durations for intervals, syllables and gaps were also measured. The time interval between the onset of one syllable and the following one is the sum of the duration of the enclosed syllable and the duration of the enclosed silence gap.

Second method: rhythm-spectrogram. A rhythm-spectrogram is a dynamic spectrum or spectrogram, a classical signal processing tool, computed at multiple time scales in a nested fashion. Rhythm analysis is used on time series of song features to study the development of rhythm over time (see [30] for more details).

The analysis was carried out by first segmenting the time period into song bouts and silence. The segmentation to bouts was done using a very low amplitude threshold that was just above noise level. The threshold levels were chosen manually according to the recording quality. We then perform spectral analysis on the feature time series corresponding to each song bout and then average the song bouts that are sung during an hour. By doing so, we are losing the information on temporal structure between bouts, but the spectral structure within a bout remains.

Song learning experiments. Pupils' songs were recorded in the absence of the tutor, when the bird was about 100dph. We analyzed song at the level of the syllables, the motif and syntax. The typical song motif was defined as the succession of syllables that includes all syllable types (except introductory notes), and occurs in a repeated manner during a song bout. Syntax refers to the sequence of syllables in many successive motifs. Motif analysis: we quantified how well pupils had copied the motif of their tutor using a similarity score and an accuracy score obtained in SAP from 100 asymmetric pairwise 
comparisons of the pupil's typical motif with the tutor motif [29]. In asymmetric comparisons, the most similar sound elements of two motifs are compared, independent of their position within a motif. The smallest unit of comparison is 9.26-ms-long sound interval (FFT windows). Each interval is characterized by measures for five acoustic features: pitch, FM, amplitude modulation (AM), Wiener entropy, and Pitch Goodness. SAP calculates the Euclidean distance between all interval pairs from two songs, over the course of the motif, and determines a p-value for each interval pair. This p-value is based on p-value estimates derived from the cumulative distribution of Euclidean distances across 250,000 sound interval pairs, obtained from 25 random pairs of zebra finch songs. Neighboring intervals that pass the $\mathrm{p}$-threshold value ( $p=0.1$ in this study) form larger similarity segments $(70 \mathrm{~ms})$. The amount of sound from the tutor's motif that was included into the similarity segments represents the similarity score; it thus reflects how much of the tutor's song material was found in the pupil's motif. To measure how accurately pupils copied the sound elements of the tutor motif, we used the accuracy score from SAP. The accuracy score is computed locally, across short (9 ms) FFT windows and indicates how well the sound matched to the sound in the tutor song. SAP calculates an average accuracy value of the motif by averaging all accuracy values across the similarity segments.

Subsyllabic structure: using the similarity procedure of Sound Analysis Pro [29], the fine structure of pupil and tutor motifs could be directly compared. We measured the duration of similar parts found in both birds for 10 selected motifs for each bird. 
Syntax analysis: for each pupil, we manually annotated sequences of syllables for at least 30 song motifs and calculated measures of syntax stereotypy (linearity and consistency) based on those published by Scharff and Nottebohm [31]. Briefly, measures of linearity quantify the number of different syllable-to-syllable transitions made for each bird by calculating the number of different syllables produced divided by the number of different syllable transitions (excluding introductory notes). Thus, a song motif with a fixed sequence of syllables in which the order is never varied (such as 'abcde') is perfectly linear and receives a score of 100 . We then measured song consistency using 4 criteria. We listed the different sequences (motifs) of syllables in the selected songs. From this list, we first calculated the percentage of motifs with the highest probability. Then, we looked at the proportion of motifs that represent the longest sequence produced by the bird. Zebra finches with a stereotyped song produce a single (canonical) motif a high proportion of the time, but frequently also produce one motif variant (such as abcdebcdebcde, where 'abcde' will be the canonical (longest) motif and 'bcde' will be the variant. Therefore, our third measure of song consistency represents the sum of the proportion of canonical motif and its variant (when produced). There are also some cases where the sequence of syllables is invariant but the bird may truncate the motif occasionally at the end of the song bout [26]. The fourth score for song consistency represents the proportion of truncated versions of the 'canonical' motif produced in the selected songs. 


\section{Crow of the Japanese quail}

To characterize vocal changes in the temporal structure of the crow, a raster plot analysis was used [32]. Briefly, we used an amplitude threshold that segmented to syllables all the sounds produced by the birds. The Japanese quail crow is composed by three syllables: two short ones followed by a long trill [32]. Syllables longer than 300ms (characteristics of the last syllable of the Japanese quail's crow) were then detected and aligned at their beginning.

\section{Rhythmicity of singing activity}

Rhythmicity of singing activity was determined by chi-square periodogram analysis [33]. Using the clustering procedure of SAP, we isolated a song syllable or a crow syllable for each bird and then calculated its occurrence for time bins of 1 min for each day of the experiment.

\section{Statistical analysis}

Changes in signal duration were estimated using the Wilcoxon matched-pairs signedranks test. Difference in song learning between groups was estimated using the Mannwhitney test. We used a general linear model to analyze the effect of LL treatment on the levels of circulating gonadal steroids in quails. The statistical package SPSS Statistics 17.0 was used for analysis. 


\section{Results}

We observed a significant shortening of the song motif duration after 2 weeks of LL (Fig. 2A-B; $P=0.017$,Wilcoxon signed-rank test). This effect seemed reversible since we observed an almost complete recovery after transfer from LL to LD 12:12 schedule (Fig. 2A-B). To quantify day-to-day changes, we used a method to calculate rhythms in birdsong that is based on motif onsets [30]. Figure 2C presents such a rhythm spectrogram for one bird. An increase of rhythm frequency occurred during the LLperiod which indicates that song motifs were shortened during this phase. A decrease in rhythm following the transfer to LD schedule indicates that song motifs became longer. For each bird, we extracted the pitch of each rhythm map to estimate the $\%$ of daily change in rhythm, i.e the difference from baseline before LL. Changes were progressive from day to day and seem to be faster in LL than during recovery (Fig. 2D).

We then investigated if the decrease in motif duration affected the duration of syllables, silent periods between syllables or both. We defined sound density as the sum of all syllable durations within a motif, and silence gaps as the sum of all silence durations within a motif. In all but one bird, sound density decreased in LL. Regarding silence gaps within the song motif, they increased in 5 birds and decreased in the 3 remaining. In LL, syllable durations decreased in $80 \%$ of the cases, silence gaps decreased in $42 \%$ of the cases, and syllable onset intervals decreased in $62 \%$ of the cases. In contrast to a previous experiment where cooling HVC affected song speed in a proportional way across all timescales [17], our experimental procedure seems to affect song timing in a non-linear way. 
This effect of LL on song length does not seem to be linked to light intensity since the song of one additional bird kept in dim light (0.1 lux) also exhibited a significant decrease in motif duration. The effect of LL was specific to the temporal pattern of the song since it did not affect pitch or other acoustic features (Table 1).

In normal conditions, singing activity exhibits a circadian pattern with a peak in the morning and no song during the dark phase [34]. Song activity became arrhythmic in LL (Fig. 3; no statistically significant periodic component could be detected using chisquare periodogram analysis). Singing activity significantly increased in LL $(P=0.012$, Wilcoxon signed-rank test) and then decreased when birds were transferred to LD 12:12 $(P=0.036$; daily number of motifs for 2 weeks period, mean $\pm \mathrm{SE}$ : before transfer in LL: $673 \pm 186$, LL: $1552 \pm 287,2$ weeks following transfer from LL: $904 \pm 212$ ).

To induce production of directed song which is faster than undirected one [26], we introduced a female in each male's cage for one hour on 2 days: one day before the photoperiod was switched to LL and the last day of LL. The presence of female induced vocal changes in both conditions: the speed rate increased with a similar magnitude (\% change; LD: $4.4 \pm 1.5, \mathrm{n}=6$; LL: $3.6 \pm 0.6, \mathrm{n}=8$ ). Therefore, LL treatment does not seem to affect the social modulation of song tempo.

To test whether this photoperiod-dependent vocal plasticity might be specific to songbirds, we repeated this experiment with a vocal non-learner species: the domestic Japanese Quail (Fig. 1B). Galliformes are at the base of the avian phylogenetic tree [35]. Adult male quails produce a stereotyped mating call (crow) that constitutes an individual signature [32]. The quail crow is usually composed of a sequence of 3 syllables: 2 short 
syllables followed by a long, final trill (Fig. 4A). Like the zebra finch song, the crow produced by the Japanese quail became shorter in LL (Fig. 4A). We used a raster-plot analysis to align all crows produced by a given individual using the beginning of the $3^{\text {rd }}$ syllable (final trill) as a reference (Fig. 4B). From these raster plots, we extracted the duration of each crow from each individual. In 9 out of 10 birds, the crow became shorter in LL (Fig. 4C, $P=0.07$, Wilcoxon signed-rank test). Following a transfer in a LD schedule, the crow became longer $(P=0.013)$, before becoming shorter again following a second transfer to LL $(P=0.028)$. Again, only the temporal pattern of this vocalization was affected by the experimental procedure; no significant changes in the acoustic structure of the crow were detected (Table 2). As in the zebra finch, duration of syllables, silence gaps and intervals did not exhibit proportional changes following the transfer to LL. In contrast to the zebra finch, crowing activity did not systematically increase in all birds in LL. Six quails decreased their vocal activity following their transfer to LL. Crows production increased again for all quails but one when photoperiod was switched to the LD schedule. Only one quail increased its vocal production following the second transfer to LL.

We observed a huge inter-individual variability in the daily rate of crow production: some quails emitted only few crows while others could produce more than 1,000 (Fig. 5). Changes in the temporal pattern of the crow cannot be explained by vocal practice since this phenomenon was observed in quails that either increase or decrease their vocal activity.

Crowing activity was arrhythmic in LL: no statistically significant periodic component could be detected using chi-square periodogram analysis. On the contrary, 
crowing activity exhibited a $24-\mathrm{h}$ rhythm when birds were raised in LD. Whereas zebra finches do not sing in darkness, quails crow at night. As reported previously [32], crows emitted at night were longer than crows produced during the day.

To determine whether LL treatment affects the levels of circulating gonadal steroids, blood samples were taken before each transfer to new photoperiodic conditions. We did not observe significant fluctuations in testosterone, estradiol and dihydrotestosterone (DHT) levels during the experiment (T: $P=0.176, \mathrm{DHT}: P=0.593$, E2: $p=0.593$, General Linear Model, repeated measures).

To explain the results observed in LL for both quails and zebra finches, there are several hypotheses that are not mutually exclusive. First, LL might have disrupted sleep patterns that are thought to be relevant for song maintenance [36]. Second, LL might be a significant stressor in animals [37]. Third, exposure to continuous light suppresses the production of melatonin [24]. In both vocal learners [18,20,21,23,38] and vocal nonlearners [39], melatonin binding sites occur in brain areas that control vocal production. In the following we investigate if this vocal flexibility might be directly linked to the hormone melatonin that could affect the temporal pattern of the mating signals.

In quails, melatonin is produced by the pineal gland and by the retina [40]. In the Zebra Finch, melatonin is mainly produced by the pineal gland [41]. In order to check whether the effects of LL might be due to suppression of melatonin production, we pinealectomized adult male zebra finches (Fig. 1C). Following pinealectomy, song motifs were shorter (Fig. 6A \& C, P=0.04, Wilcoxon signed-rank test). No significant effect on the temporal pattern of the song was observed in sham-pinealectomized birds (Fig. 6B-C, 
$P=0.08$ ). A rhythm-spectrogram for one bird (Fig. 6D) shows an increase in frequency rhythm following pinealectomy indicating a decrease in motif duration following the surgery. We observed an increase of frequency in each bird that tends to stabilize about 45 days following pinealectomy (Fig. 6E). No significant changes were observed following sham surgery (Fig. 6F). We then investigated if the decrease in motif duration affected the duration of syllables, silence periods between syllables or both. In all birds, sound density decreased following pinealectomy. Regarding silence gaps within the song motif, they increased in 3 birds and slightly decreased in the 2 remaining ones. Overall, following pinealectomy, syllable durations decreased in $88 \%$ of the cases, silence gaps decreased in $32 \%$ of the cases, and syllable onset intervals decreased in $63 \%$ of the cases. Like in LL, pinealectomy seems to affect song timing in a non-linear way. Pinealectomy did not affect the spectral components (e.g. pitch) of the song motifs (Table 3). Regarding song activity, it decreased following surgery but went back to baseline later showing that the changes in song motif duration were not due to practice.

One month after the surgery, we introduced a female in the cage of each male to induce directed singing. We observed an additional increase in the speed of song delivery in pinealectomized birds ( $\mathrm{n}=3 ; 4.6,2.8$ and $2.8 \%$ faster than undirected song).

One cohort of zebra finches was treated with melatonin, using a skin cream [25], applied just before lights off. We used intact $(n=6)$, sham $(n=5)$ and pinealectomized finches $(n=5)$. The next morning, the songs of control birds (sham and intact birds) were longer than those produced the previous day (Fig. 7A, $P=0.005$, Wilcoxon signed-rank test). No significant changes in motif duration were observed following treatment with a placebo cream (Fig. $7 \mathrm{~B}, P=0.86$ ). The song motif of pinealectomized birds was also 
longer following melatonin treatment $(P=0.043)$, but it did not recover the duration value measured before pinealectomy.

Interestingly, the number of melatonin binding sites in the song control system increases during the sensitive period for vocal learning [23]. This suggests that melatonin may play a role in vocal learning. To investigate the effects of melatonin on song learning, young male zebra finches were raised with one adult male during the sensitive phase for vocal learning (dph43-100). Both birds were kept under LL during the whole experiment (Fig. 1D). Young males exhibited significant vocal changes and learning. We observed that some pupils were able to produce accurate copies of sounds produced by their tutor, showing that LL does not impair vocal learning completely (Fig. 8A). However, their imitation was worse than those produced by control birds raised in a LD schedule (Fig. 8B-C, $P=0.008$, Mann Whitney). Song segments as short as $5-10 \mathrm{~ms}$ are independently produced [11]. We segmented song motifs into notes, and compared note similarity between each pupil and his respective tutor. We observed that notes produced by pupils were shorter than those produced by their tutor (Fig. 8D, $P=0.016$ ). Song syntax stereotypy (temporal sequence of syllables) was impaired for 2 out of the 5 finches trained to learn a song in LL, but was high in the 3 remaining birds (Table 4). As previously mentioned, several reasons could explain this result. LL might have stressed the birds and might have also disrupted sleep patterns that appear to be relevant for song learning $[34,42]$. The young male was also trying to imitate a 'moving target' since the song duration of its tutor decreased during the experiment (duration $(\mathrm{ms})$, mean \pm s.e.m: 
before transfer in LL: $489 \pm 35$, last day of LL: $468 \pm 33$ ). Finally, suppression of melatonin production in LL might have impaired song learning.

To investigate the impact of melatonin on song learning, we pinealectomized young male zebra finches (dph 38-42), before exposing them to a single adult male tutor while maintaining them in LD (Fig. 1E). Like in LL, pinealectomized birds were sometimes able to imitate accurately syllables of their tutor (Fig. 8E). We did not observe significant difference in the quality of imitation with sham-pinealectomized birds (Fig. 8F-G, $P=0.8$, Mann-Whitney). However, as in LL, the temporal pattern of the song was affected by pinealectomy. The duration of notes produced by pinealectomized birds was shorter than those of their tutor $(p=0.01)$; no significant difference was observed for sham birds (Fig. 8H). For both groups, song syntax stereotypy was impaired in 2 out of 6 finches, showing that the effect does not concern the temporal sequence of syllables per se (Table 5).

Some studies have demonstrated the active role of sleep on the developmental learning of birdsong [34,41]. Post night-sleep deterioration of song structure is observed in young zebra finches that learn to sing, and disappears as soon as the bird starts to produce a mature version of the song [34]. In 5 out of 6 birds (the sixth bird did not exhibit signs of vocal imitation), we observed an overnight deterioration of song structure. These results indicate that melatonin might have a minor role in this type of vocal plasticity. 


\section{Discussion}

Taken together, these results suggest that melatonin affects the temporal pattern of the zebra finch song and the Japanese quail crow, two vocalizations composed of a stereotyped sequence of syllables, which are used as individual signatures in courtship displays. This effect was specific to the motor timing of the signal since LL and pinealectomy did not affect spectral features of syllables or the stereotypy of their order. These experimental procedures also impaired song learning in melatonin-deprived young finches. Again, the temporal pattern of the song was mainly affected since some birds produced shortened versions of the sounds produced by their tutor.

Our experimental procedures appear suitable to investigate the mechanism of timing control of vocal signals in birds. In both vocal learner and non-learner species, a central pattern generator $(\mathrm{CPG})$ network likely controls vocalizations [44]. In quails, a midbrain nucleus, the nucleus intercollicularis (ICo) is considered to be at the head of the vocal control system [44]. The ICo sends axonal projections to the hindbrain regions involved in the control of the vocal organ and in respiratory control [44]. In contrast, the CPG network for song includes the telencephalon that is afferent to the midbrain and hindbrain vocal control regions $[45,46]$. In both vocal learner and vocal non learner species, many areas of the respective vocal control pathways are targets of melatonin due to the presence of melatonin receptors $[18,20,21,23,38,39]$. Thus the similar effects of melatonin on the temporal pattern of the zebra finch song and the Japanese quail crow could be due either to melatonin acting in common midbrain and hindbrain song control regions, or to melatonin sensitive mechanisms taking place in different brain regions of 
zebra finches and quails. Common forebrain melatonin sensitive mechanisms to both species are unlikely due to the lack of forebrain vocal control regions in quails.

In the zebra finch, two forebrain nuclei in particular have been implicated in the control of the temporal structure of song: HVC (proper name) and RA (robust nucleus of the arcopallium). Both HVC and RA neurons express melatonin receptors [18,23]. Single-unit recordings in HVC show that each neurons projecting to RA produces a single burst of spikes at a particular time in the song [9]. Fee et al. [47] have proposed that each HVC neuron acts like a single 'clock', continuously pacing song behaviour. However, behavioral data demonstrate that syllables and gaps scale differently with changes in song tempo, and that variations in syllable and gap lengths are correlated with other intervals of the same type [11]. Following transfer into LL and pinealectomy, we did not observe a proportional scaling of syllable and silence gap lengths. Glaze and Troyer [11] proposed that the departure from proportional scaling could also occur when clock-like activity in RA projection neurons interacts with the brainstem premotor nuclei for song production. Portions of the midbrain and respiratory areas project back to HVC through thalamic nucleus uvaeformis (Uva, [46]), raising the further possibility that syllables, which are tightly linked to respiratory patterning [48], may be timed by respiratory oscillator circuits [49]. Application of melatonin to brain slices decreases the firing rate of RA neurons [18]. Thus, the nightly action of melatonin could affect the song pattern of the next day via some unknown mechanism changing the electrical neuronal properties in several brain vocal areas including both forebrain and midbrain/hindbrain areas. Further, the recovery from melatonin deprivation in LL is rather slow taking about two weeks or more. This suggests a second (slower-acting) melatonin sensitive 
mechanism of song control that might concern the photoperiod-dependent density of melatonin receptors in different brain areas [50] including vocal control regions [21].

In quails, the effect of melatonin described here could occur either in the midbrain and hindbrain vocal control regions. There is no direct evidence of an effect of melatonin on these neuron populations and melatonin receptors have so far been suggested only for the midbrain ICo [39]. Nevertheless, the present experimental evidence of melatonin sensitivity of the temporal pattern of the crow is further supported by a natural dataset: the nightly courtship calling behaviour of quails. Crows emitted at night are longer than crows produced during the day [32]. This suggests that melatonin has an immediate effect on the vocal motor timing. It is worth mentioning that we observed similar vocal changes (decrease of crow duration, no proportional scaling of syllables and silence gap lengths) in quails whose vocalizations are not controlled by the forebrain nuclei. Despite direct evidence of an effect of melatonin on forebrain nuclei in the zebra finch, similar melatonin-dependent mechanisms could occur in parts of the vocal control pathway common to both species.

Our study also reveals that melatonin affects sensorimotor learning of birdsong. During song learning, young birds memorize a tutor song and use it as a template to shape their own song [51]. The failure in copying the temporal pattern of the tutor song might therefore stem both from effects at the perceptual and at the production level. Melatonin may influence learning and memory processes through structural remodeling of synaptic connections [52]. As suggested for many species including humans, declining melatonin levels caused by pineal attrition may also play a role in the loss of brain plasticity [53]. For example, pineal dysfunction has been linked to learning disabilities in 
autistic children [54]. The role of brain plasticity on song learning has been recently evidenced in the zebra finch [55]. Sleep-related plasticity has also been described in young finches that learn to sing [34,42]. In birds, melatonin administration can induce sleep [56] and neural song replay occurs readily in this induced sleep state in zebra finches [9]. Although we did not detect an effect of pinealectomy on overnight vocal changes related to sleep, more experiments are required to evaluate the effects of melatonin on sleep patterns in the zebra finch. Therefore, despite its possible role on brain plasticity, it is more likely that melatonin affects the same mechanisms in juvenile as in adult zebra finches: a reduced precision of motor timing that would then cause reduced sensorimotor learning.

Finally, these results could be of interest in light of the sexual selection theories. The song of the zebra finch and the crow of the Japanese quail are two individual signatures that are used to maintain contact with other conspecifics and their mates, but they are also an integral feature of male courtship behaviour and subject to female mate selection $[6,27,32,57]$. Effects on both vocalizations that depend on gonadal production of sex hormones are rather slow and long lasting [58-59]. By contrast, the transient effects of melatonin could mediate day-to-day changes in the socio-sexual context, and could exhibit honest signal value of these vocalizations. This interpretation remains however speculative due to the lack of detailed knowledge concerning the control of the melatonin production of birds other than the photoperiod [60]. 


\section{Acknowledgements}

We thank W. Goymann for providing the melatonin cream; K. Spoelstra and A. ter Maat for statistical assistance; W. Jensen for technical assistance; J. Minshull for animal care; I. Schwabl and M. Trappschuh for hormone analysis. B. Helm, A. ter Maat, N. Rattenborg and O. Tchernichovski gave valuable comments on previous versions of the manuscript. This work was supported by the Max Planck Society.

\section{Author Contributions}

SD and MG designed research. SD performed research. SD and SS analyzed data. SD and MG wrote the paper.

\section{References}

1. BROWN S, MARTINEZ MJ, PARSONS LM. The neural basis of human dance. Cereb Cort 2006; 16: 1157-1167.

2. FELDMAN JL, DEL NEGRO CA. Looking for inspiration: new perspectives on respiratory rhythm. Nat Rev Neurosci 2006; 7: 232-242.

3. ZATORRE RJ, CHEN JL, PENHUNE VB. When the brain plays music: auditorymotor interactions in music perception and production. Nat Rev Neurosci 2007; 8: 547558.

4. LI WC, ROBERTS A, SOFFE SR Locomotor rhythm maintenance: electrical coupling among premotor excitatory interneurons in the brainstem and spinal cord of young Xenopus tadpoles. J Physiol 2009; 587: 1677-1693. 
5. NOTTEBOHM F, STOKES TM, LEONARD CM. Central control of song in Canary Serinus canarius. J Comp Neurol 1976; 165: 457-486.

6. BRAINARD MS, DOUPE AJ. What songbirds teach us about learning. Nature 2002; 417: $351-358$.

6. SOSSINKA R, BOEHNER J. Song types in the Zebra finch Poephila guttata castanotis. Zeit Tierpsychol 1980; 53: 123-132.

7. GLAZE CM, TROYER TW. Temporal structure in Zebra Finch song: implications for motor coding. J Neurosci 2006; 26: 991-1005.

8. YU AC, MARGOLIASH D. Temporal hierarchical control of singing in birds. Science 1996; 273: 1871-1875.

9. HAHNLOSER RHR, KOZHEVNIKOV AA, FEE MS. An ultra-parse code underlies the generation of neural sequences in a songbird. Nature 2002; 419: 65-70.

10. SOLIS MM, PERKEL DJ. Rhythmic activity in a forebrain vocal control nucleus in vitro. J Neurosci 2005; 25: 2811-2822.

11. GLAZE CM, TROYER TW. Behavioral measurements of a temporally precise motor code for birdsong. J Neurosci 2007; 27: 7631-7639.

12. LONG MA, JIN DZ, FEE MS Support for a synaptic chain model of neuronal sequence generation. Nature 2010; 468: 394-399.

13. WILLIAMS H, MEHTA N. Changes in adult zebra finch song require a forebrain nucleus that is not necessary for song production. J Neurobiol 1999; 39: 14-28.

14. NORDEEN KW, NORDEEN EJ. Auditory feedback is necessary for the maintenance of stereotyped song in adult zebra finches. Behav Neural Biol 1992; 57: 58-66. 
15. LEONARDO A, KONISHI M. Decrystallization of adult birdsong by perturbation of auditory feedback. Nature 1999; 399: 466-470.

16. ANDALMAN AS, FEE MS. A basal ganglia-forebrain circuit in the songbird biases motor output to avoid vocal errors. Proc Natl Acad Sci USA 2009; 106: 12518-12523.

17. LONG MA, FEE MS. Using temperature to analyse temporal dynamics in the songbird motor pathway. Nature 2008; 456: 189-194.

18. JANSEN R, METZDORF R, VAN DER ROEST M, et al. Melatonin affects the temporal organization of the song of the zebra finch. FASEB J 2005; 19: 848-850.

19. TAN DX, HARDELAND R, MANCHESTER LC, et al. The changing biological roles of melatonin during evolution: from an antioxidant to signals of darkness, sexual selection and fitness. Biol Rev Camb Phil Soc 2009; 85: 607-623.

20. WHITFIELD-RUCKER MG, CASSONE VM. Melatonin binding in the house sparrow song control system: sexual dimorphism and the effect of photoperiod. Horm Behav 1996; 30: 528-537.

21. BENTLEY GE, BALL GF. Photoperiod-dependent and -independent regulation of melatonin receptors in the forebrain of songbirds. J Neuroendocrinol 2000; 12: 745-752.

23. GAHR M, KOSAR E. Identification, distribution, and developmental changes of a melatonin binding site in the song control system of the zebra finch. J Comp Neurol 1996; 367: 308-318.

24. YAMADA H, OSHIMA I, SATO K, et al. Loss of the circadian rhythms of locomotor activity, food intake, and plasma melatonin concentration induced by constant bright light in the pigeon (Columba livia). J Comp Physiol 1988; 163: 459463. 
25. GOYMANN W, TRAPPSCHUH M, FUSANI L. A gentler method to raise melatonin levels in birds. J Biol Rhythms 2008; 23: 274-277.

26. KAO MH, BRAINARD MS. Lesions of an avian basal ganglia circuit prevent context-dependent changes to song variability. J Neurophysiol 2006; 96: 1441-1455.

27. DEREGNAUCOURT S. Birdsong learning in the laboratory, with especial reference to the song of the Zebra Finch (Taeniopygia guttata). Interact Stud 2011; 12: 323-349.

28. TCHERNICHOVSKI O, LINTS TJ, DEREGNAUCOURT S, et al. Studying the song development process: rationale and methods. Ann NY Acad Sci 2004; 1016: 348-363.

29. TCHERNICHOVSKI O, NOTTEBOHM F, HO CE, et al. A procedure for an automated measurement of song similarity. Anim Behav 2000; 59: 1167-1176.

30. SAAR S, MITRA PP. A technique for characterizing the development of rhythms in bird song. PloSOne 2008; 3: e1461.

31. SCHARFF C, NOTTEBOHM F. A comparative study of the behavioral deficits following lesions of various parts of the zebra finch song system: implications for vocal learning. J Neurosci 1991; 11: 2896-2913.

32. DEREGNAUCOURT S, SAAR S, GAHR M. Dynamics of crowing development in the domestic Japanese quail (Coturnix coturnix japonica). Proc Roy Soc Lond B 2009; 276: $2153-2162$.

33. SOKOLOVE PG, BUSHELL WN. The chi square periodogram: Its utility for analysis of circadian rhythms. J Theor Biol 1978; 72: 131-160.

34. DEREGNAUCOURT S, MITRA PP, FEHER O, et al. How sleep affects the developmental learning of bird song. Nature 2005; 433: 710-716. 
35. HACKETT SJ, KIMBALL RT, REDDY S, et al. A phylogenomic study of birds reveals their evolutionary history. Science 2008; 320: 1763-1768.

36. RAUSKE PL, CHI Z, DAVE AS, et al. Neuronal stability and drift across periods of sleep: premotor activity patterns in a vocal control nucleus of adult zebra finches. J Neurosci 2010; 30: 2783-2794.

37. MA W-P, CAO J, TIAN M, et al. Exposure to chronic LL impairs spatial memory and influences long-term depression in rats. Neurosci Res 2007; 59: 224-230.

38. BENTLEY GE, VAN'T HOF TJ, BALL GF. Seasonal neuroplasticity in the songbird telencephalon: a role for melatonin. Proc Natl Acad Sci USA 1999; 96: 4674-4679.

39. ASTE N, COZZI B, STANKOV B, et al. Sexual differences and effect of photoperiod on melatonin receptor in avian brain. Microsc Res Tech 2001; 55: 37-47.

40. UNDERWOOD H, SIOPES T. Melatonin rhythms in quail: regulation by photoperiod and circadian pacemakers. J Pineal Res 1985; 2: 133-143.

41. VAN'T HOF TJ, GWINNER E. Influence of pinealectomy and pineal stalk deflection on circadian gastrointestinal tract melatonin rhythms in zebra finches (Taeniopygia guttata). J Biol Rhythms 1999; 14: 185-189.

42. SHANK SS, MARGOLIASH D. Sleep and sensorimotor integration during early vocal learning in a songbird. Nature 2009; 458: 73-77.

43. KONISHI M. From central pattern generator to sensory template in the evolution of birdsong. Brain Lang 2010; 115: 18-20.

44. SHAW BK. Involvement of a midbrain vocal nucleus in the production of both the acoustic and postural components of crowing behavior in Japanese quail. J Comp Physiol A 2000; 186: 747-757. 
45. WILD JM, Li D, EAGLETON C. Projections of the dorsomedial nucleus of the intercollicular complex (DM) in relation to respiratory-vocal nuclei in the brainstem of pigeon (Columba livia) and zebra finch (Taeniopygia guttata). J Comp Neurol 1997; 377: $392-413$.

46. ASHMORE RC, RENK JA, SCHMIDT MF. Bottom-up activation of the vocal motor forebrain by the respiratory brainstem. J Neurosci 2008; 28: 2613-2623.

47. FEE MS, KOZHEVNIKOV AA, HAHNLOSER RHR. Neural mechanisms of vocal sequence generation in the songbird. Ann NY Acad Sci 2004; 1016: 153-170.

48. GOLLER F, COOPER BG. Peripheral motor dynamics of song production in the zehra finch. Ann NY Acad Sci 2004; 1016: 130-152.

49. ASHMORE RC, WILD JM, SCHMIDT MF. Brainstem and forebrain contributions to the generation of learned motor behaviors for song. J Neurosci 2005; 25: 8543-8554.

50. PANZICA GC, FRASCHINI F, ASTE N, et al. The density of melatonin receptors is dependent upon the prevailing photoperiod in the Japanese quail (Coturnix japonica). Neurosci Lett 1994; 173: 111-114.

51. KONISHI M. The role of auditory feedback in the control of vocalization in the White-Crowned Sparrow. Zeit Tierpsychol 1965; 22: 770-783.

52. BAYDAS G, NEDZVETSKY VS, NERUSH PA, et al. A novel role for melatonin: regulation of the expression of cell adhesion molecules in the rat hippocampus and cortex. Neurosci Lett 2002; 326: 109-112.

53. YUN AJ, BAZAR KA, LEE PY. Pineal attrition, loss of cognitive plasticity, and onset of puberty during the teen years: is it a modern maladaptation exposed by evolutionary displacement? Med Hypotheses 2004; 63: 939-950. 
54. MELKE J, GOUBRAN BOTROS H, CHASTE P, et al. Abnormal melatonin synthesis in autism spectrum disorders. Mol Psychiatry 2008; 13: 90-98.

55. ROBERTS TF, TSCHIDA KA, KLEIN ME, et al. Rapid spine stabilization and synaptic enhancement at the onset of behavioural learning. Nature 2010; 463: 948-952.

56. MINTZ EM, PHILLIPS NH, BERGER RJ. Daytime melatonin infusions induce sleep in pigeons without altering subsequent amounts of nocturnal sleep. Neurosci Lett 1998; 258: 61-64.

57. DEREGNAUCOURT S, GUYOMARC'H J-C. Mating call discrimination in female European (Coturnix c. coturnix) and Japanese quail (Coturnix c. japonica). Ethology 2003; 109: 107-119.

58. ARNOLD AP. The effects of castration and androgen replacement on song, courtship and aggression in zebra finches. J Exp Zool 1975; 191: 301-325.

59. BEANI L, BRIGANTI F, CAMPANELLA G, et al. Effect of androgens on structure and rate of crowing in the Japanese quail (Coturnix japonica). Behav 2000; 137: 417435.

60. GAHR M. Hormone-dependent neural plasticity in the juvenile and adult song system: What makes a successful male? Ann NY Acad Sci 2004; 1016: 684-703. 


\section{Figure legends}

Fig. 1. Schematic representations of the experimental procedures. (A) Adult finches in constant light. (B) Adult quails in constant light. (C) Pinealectomy experiment with adult finches. (D) Song learning experiment with finches in constant light. (E) Song learning following pinealectomy in finches. Dph: day post hatching. LD: light/dark schedule. LL: constant light. CON: control group. PINX and SHAM: pinealectomy and sham surgery.

Fig. 2. Song becomes shorter in constant light (LL). (A) Spectrograms of a song motif produced by a zebra finch. Top: before transfer to LL; middle: after 2 weeks of LL; bottom: two weeks after the transfer to normal light-dark (LD 12:12) schedule. (B) Individual values for motif duration produced during the three stages of the experiment. (C) Rhythm-spectrogram for a bird transferred to LL. (D) Percent of rhythm changes during the experiment.

Fig. 3. Singing activity of zebra finches in constant light. (A) Song-actogram of one bird before, during and after transfer to LL. Right part of the graph: chi-square periodograms. (B) Daily number of song motifs produced during the experiment.

Fig. 4. Crow becomes shorter in constant light (LL). (A) Spectrograms of crows produced by an adult quail transferred twice from a normal light-dark schedule to LL. (B) Raster plot calculated for the entire experiment. Colour indicates amplitude values. Each horizontal line in a plot represents one crow. Crows were aligned at $600 \mathrm{~ms}$ by the 
occurrence of the third syllable. Red arrows indicate the time when the quail was transferred in LL. In this case, the bird produced 844 crows during the experiment. (C) Changes in crow duration (mean \pm s.e.m) during the experiment.

Fig. 5. Crowing activity of Japanese quails maintained in constant light (LL). The grey area indicates the time when quails were transferred to LL.

Fig. 6. Song becomes shorter following pinealectomy. (A) Spectrograms of a song motif before and after pinealectomy. (B) Spectrograms of a song motif before and after shampinealectomy. (C) Motif duration for 5 pinealectomized and 5 sham-pinealectomized birds before and after the surgery. (D) Rhythm-spectrogram of a pinealectomized bird. (E) Percent of rhythm changes following pinealectomy. The red arrow indicates the time point when surgery was done. (F) Percent of rhythm change following shampinealectomy. The red arrow indicates the time point when surgery was done.

Fig. 7. Song becomes longer following melatonin treatment. (A) Motif duration before and after skin application of melatonin. (B) Motif duration before and after skin application of a placebo cream.

Fig. 8. Song learning is impaired in birds raised in constant light (LL) and in pinealectomized birds. (A) Spectrograms of song produced by the best pupil and its tutor; both birds were maintained in LL during the sensitive phase of song learning for the pupil. (B) Percent of song similarity between pupil-tutor pairs, for birds raised in LL and 
control birds maintained in LD 12:12. (C) Percent of song accuracy between pupil-tutor pairs, for birds raised in LL and control birds maintained in LD 12:12. (D) Difference in notes durations (absolute values) produced by pupil and their respective tutor, for birds maintained in LL and control birds. (E) Spectrograms of song produced by the best pupil and its tutor; the pupil was pinealectomized few days before the introduction of the tutor in its cage. (F) Percent of song similarity between pupil-tutor pairs, for birds pinealectomized (PINX) and control birds that were sham-pinealectomized (SHAM). (G) Percent of song accuracy between pupil-tutor pairs, for PINX and SHAM birds. (H) Difference in notes durations (absolute values) produced by pupil and their respective tutor, for both conditions. *: $P<0.05$. 
Table 1. Spectral features of the zebra finch song are not affected following transfer in constant light.

\begin{tabular}{|l|c|c|c|}
\hline \multicolumn{1}{|c|}{ Acoustic feature } & $\begin{array}{c}\text { Before } \mathbf{L L} \\
(\text { mean } \pm \text { SE) }\end{array}$ & $\begin{array}{c}\text { After LL } \\
(\text { mean } \pm \text { SE) }\end{array}$ & (mean \pm SE) \\
\hline Mean pitch (Hz) & $1007 \pm 62$ & $1004 \pm 65$ & $1030 \pm 70$ \\
Mean FM & $40.4 \pm 1.3$ & $41.1 \pm 1.4$ & $41 \pm 1.5$ \\
Mean AM (x10-5) & $506 \pm 7$ & $508 \pm 8$ & $510 \pm 7$ \\
Mean entropy & $-2.21 \pm 0.07$ & $-2.17 \pm 0.07$ & $-2.15 \pm 0.07$ \\
Mean pitch goodness & $507 \pm 46$ & $522 \pm 50$ & $506 \pm 54$ \\
Mean mean frequency (Hz) & $3387 \pm 66$ & $3426 \pm 62$ & $3418 \pm 30$ \\
Variance pitch (kHz) & $1754 \pm 212$ & $1804 \pm 206$ & $1833 \pm 217$ \\
Variance FM & $679 \pm 27$ & $679 \pm 25$ & $667 \pm 33$ \\
Variance AM (x10-5) & $556 \pm 73$ & $550 \pm 55$ & $528 \pm 85$ \\
Variance entropy & $1.26 \pm 0.1$ & $1.27 \pm 0.13$ & $1.19 \pm 0.11$ \\
Variance pitch goodness (kHz) & $188 \pm 24$ & $204 \pm 29$ & $187 \pm 29$ \\
Variance mean frequency (kHz) & $509 \pm 64$ & $563 \pm 40$ & $467 \pm 30$ \\
& & & \\
\hline
\end{tabular}


Table 2. Spectral features of the Japanese quail crow are not affected following transfer in constant light.

\begin{tabular}{|l|c|c|c|c|c|}
\hline \multicolumn{1}{|c|}{ Acoustic feature } & $\begin{array}{c}\text { Before LL1 } \\
(\text { mean } \pm \text { SE) }\end{array}$ & $\begin{array}{c}\text { LL1 } \\
(\text { mean } \pm \text { SE) }\end{array}$ & $\begin{array}{c}\text { After LL1 } \\
(\text { mean } \pm \text { SE) }\end{array}$ & $\begin{array}{c}\text { Before LL2 } \\
(\text { mean } \pm \text { SE) }\end{array}$ & $\begin{array}{c}\text { LL2 } \\
(\text { mean } \pm \text { SE) }\end{array}$ \\
\hline Mean FM & $47.6 \pm 1.5$ & $47.3 \pm 1.8$ & $46.4 \pm 1.3$ & $48.3 \pm 1.2$ & $47 \pm 3$ \\
Mean AM $\left(\mathbf{x 1 0}^{-3}\right)$ & $4469 \pm 339$ & $4419 \pm 304$ & $4251 \pm 353$ & $4546 \pm 250$ & $4460 \pm 394$ \\
Mean entropy & $-3.63 \pm 0.34$ & $-3.71 \pm 0.07$ & $-3.45 \pm 0.07$ & $-2.95 \pm 0.07$ & $-3.35 \pm 0.07$ \\
Mean mean frequency (Hz) & $2014 \pm 111$ & $1974 \pm 77$ & $2064 \pm 107$ & $2195 \pm 113$ & $2227 \pm 241$ \\
Variance FM & $541 \pm 18$ & $513 \pm 16$ & $546 \pm 20$ & $520 \pm 22$ & $484 \pm 37$ \\
Variance AM (x10-3) & $4310 \pm 332$ & $4291 \pm 293$ & $4404 \pm 312$ & $4547 \pm 307$ & $4187 \pm 391$ \\
Variance entropy & $0.65 \pm 0.09$ & $0.69 \pm .0 .09$ & $0.61 \pm 0.12$ & $0.52 \pm 0.11$ & $0.47 \pm 0.11$ \\
Variance mean frequency & $298 \pm 72$ & $189 \pm 28$ & $250 \pm 51$ & $258 \pm 34$ & $210 \pm 72$ \\
(kHz) & & & & & \\
\hline
\end{tabular}


Table 3. Spectral features of the zebra finch song are not affected following pinealectomy.

\begin{tabular}{|l|c|c|c|c|}
\hline \multicolumn{1}{|c|}{ Acoustic feature } & Before & After & Before & After \\
& $($ mean \pm SE) & $($ mean \pm SE) & $($ mean \pm SE) & (mean \pm SE) \\
\hline Mean pitch (Hz) & $985 \pm 103$ & $1004 \pm 65$ & $1173 \pm 141$ & $1181 \pm 136$ \\
Mean FM & $35.4 \pm 3.8$ & $41.1 \pm 1.4$ & $40.9 \pm 2.4$ & $40.9 \pm 2.1$ \\
Mean AM (x10-5) & $407 \pm 7$ & $392 \pm 14$ & $407 \pm 5$ & $406 \pm 8$ \\
Mean entropy & $-2.22 \pm 0.01$ & $-2.05 \pm 0.14$ & $-2.25 \pm 0.12$ & $-2.2 \pm 0.12$ \\
Mean pitch goodness & $486 \pm 53$ & $472 \pm 45$ & $413 \pm 29$ & $417 \pm 39$ \\
Mean mean frequency (Hz) & $3472 \pm 177$ & $3374 \pm 128$ & $3731 \pm 62$ & $3793 \pm 106$ \\
Variance pitch (kHz) & $2109 \pm 376$ & $1911 \pm 481$ & $2475 \pm 435$ & $2485 \pm 458$ \\
Variance FM & $649 \pm 38$ & $598 \pm 28$ & $636 \pm 16$ & $645 \pm 22$ \\
Variance AM (x10-5) & $537 \pm 93$ & $527 \pm 94$ & $588 \pm 65$ & $586 \pm 67$ \\
Variance entropy & $1.11 \pm 0.1$ & $0.92 \pm 0.12$ & $1.34 \pm 0.15$ & $1.3 \pm 0.14$ \\
Variance pitch goodness (kHz) & $170 \pm 39$ & $158 \pm 35$ & $143 \pm 11$ & $147 \pm 13$ \\
Variance mean frequency (kHz) & $429 \pm 56$ & $501 \pm 31$ & $403 \pm 43$ & $436 \pm 66$ \\
& & & & \\
\hline
\end{tabular}


Table 4. Song syntax stereotypy is not affected by constant light.

There are four measures for song consistency (in \%): 1) motif produced with the highest probability; 2) probability of occurrence of the longest motif; 3) probability of occurrence of the canonical motif and its variant (when produced); 4) truncated versions of the motif.

\begin{tabular}{|c|c|c|c|c|c|c|c|c|c|c|}
\hline & \multicolumn{5}{|c|}{ LL } & \multicolumn{5}{c|}{ Control } \\
\hline & Linearity & \multicolumn{3}{|c|}{ Consistency } & \multicolumn{2}{c|}{ Linearity } & \multicolumn{3}{c|}{ Consistency } \\
\hline Bird & & $\mathbf{1}$ & $\mathbf{2}$ & $\mathbf{3}$ & $\mathbf{4}$ & & $\mathbf{1}$ & $\mathbf{2}$ & $\mathbf{3}$ & $\mathbf{4}$ \\
\hline $\mathbf{1}$ & 100 & 100 & 100 & & 0 & 100 & 100 & 100 & & 0 \\
\hline $\mathbf{2}$ & 100 & 100 & 100 & & 0 & 100 & 100 & 100 & & 0 \\
\hline $\mathbf{3}$ & 100 & 100 & 100 & & 0 & 100 & 69.6 & 69.6 & & 30.4 \\
\hline $\mathbf{4}$ & 54.5 & 39.5 & 27.9 & & 11.6 & 100 & 67.9 & 32.1 & & 32.1 \\
\hline $\mathbf{5}$ & 26.9 & 9.6 & 9.6 & & 0 & 80 & 44.8 & 44.8 & 72.4 & 27.6 \\
\hline
\end{tabular}


Table 5. Song syntax stereotypy is not affected by pinealectomy.

There are four measures for song consistency (in \%): 1) motif produced with the highest probability; 2) probability of occurrence of the longest motif; 3) probability of occurrence of the canonical motif and its variant (when produced); 4) truncated versions of the motif.

\begin{tabular}{|c|c|c|c|c|c|c|c|c|c|c|}
\hline & \multicolumn{5}{|c|}{ PINX } & \multicolumn{5}{c|}{ SHAM } \\
\hline & Linearity & \multicolumn{3}{|c|}{ Consistency } & Linearity & \multicolumn{3}{c|}{ Consistency } \\
\hline Bird & & $\mathbf{1}$ & $\mathbf{2}$ & $\mathbf{3}$ & $\mathbf{4}$ & & $\mathbf{1}$ & $\mathbf{2}$ & $\mathbf{3}$ & $\mathbf{4}$ \\
\hline $\mathbf{1}$ & 100 & 100 & 100 & & 0 & 100 & 93.3 & 93.3 & & 6.7 \\
\hline $\mathbf{2}$ & 100 & 73.3 & 73.3 & & 26.7 & 100 & 91.2 & 91.2 & & 8.8 \\
\hline $\mathbf{3}$ & 100 & 44.1 & 35.3 & 79.4 & 20.6 & 100 & 56.7 & 43.3 & & 56.7 \\
\hline $\mathbf{4}$ & 100 & 37.5 & 37.5 & 53.1 & 46.9 & 100 & 41.5 & 31.7 & 73.2 & 26.8 \\
\hline $\mathbf{5}$ & 42.9 & 47.8 & 17.4 & & 82.6 & 87.5 & 48.8 & 34.1 & & 61 \\
\hline $\mathbf{6}$ & 42.9 & 41.9 & 71 & & 9.7 & 50 & 71 & 71 & & 27 \\
\hline
\end{tabular}


A

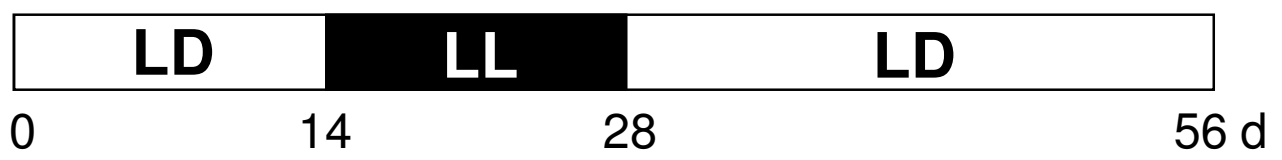

B

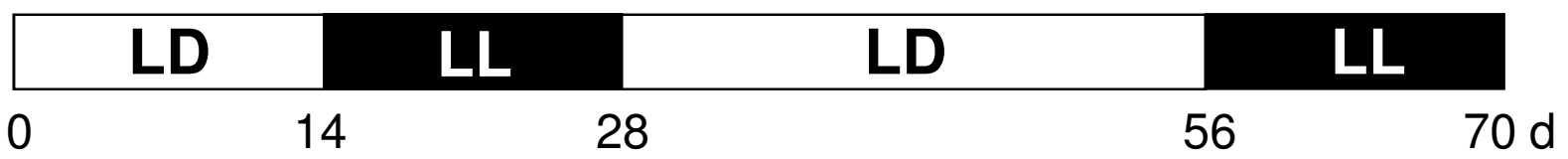

C

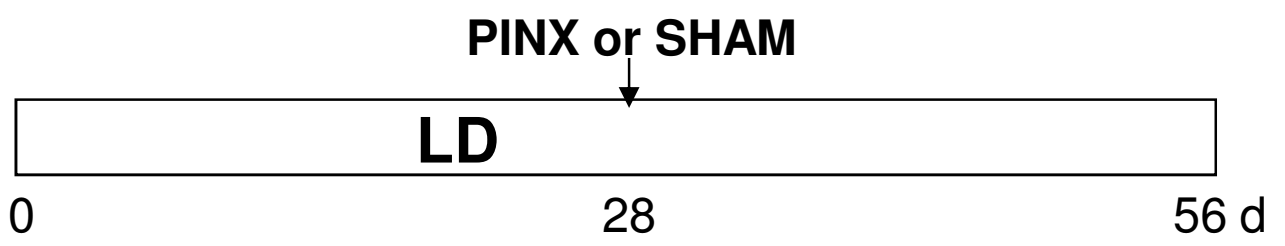

D

CON

LD

LL $\quad$ LD $\quad$ LL

\begin{tabular}{l|l|l|l|}
$\begin{array}{l}\text { raised by } \\
\text { parents }\end{array}$ & $\begin{array}{l}\text { raised by } \\
\text { mother }\end{array}$ & $\begin{array}{l}\text { social } \\
\text { isolation }\end{array}$ & with adult tutor \\
0 & 14 & $30 \quad 43$ & $100 \mathrm{dph}$
\end{tabular}

E

\section{LD}

\begin{tabular}{|c|c|c|c|}
\hline \begin{tabular}{|l} 
raised by \\
parents
\end{tabular} & $\begin{array}{l}\text { raised by } \\
\text { mother }\end{array}$ & \begin{tabular}{|l|} 
social \\
isolation
\end{tabular} & with adult tutor \\
\hline 0 & & 3038 & \\
\hline
\end{tabular}

Figure 1 - Derégnaucourt et al. 

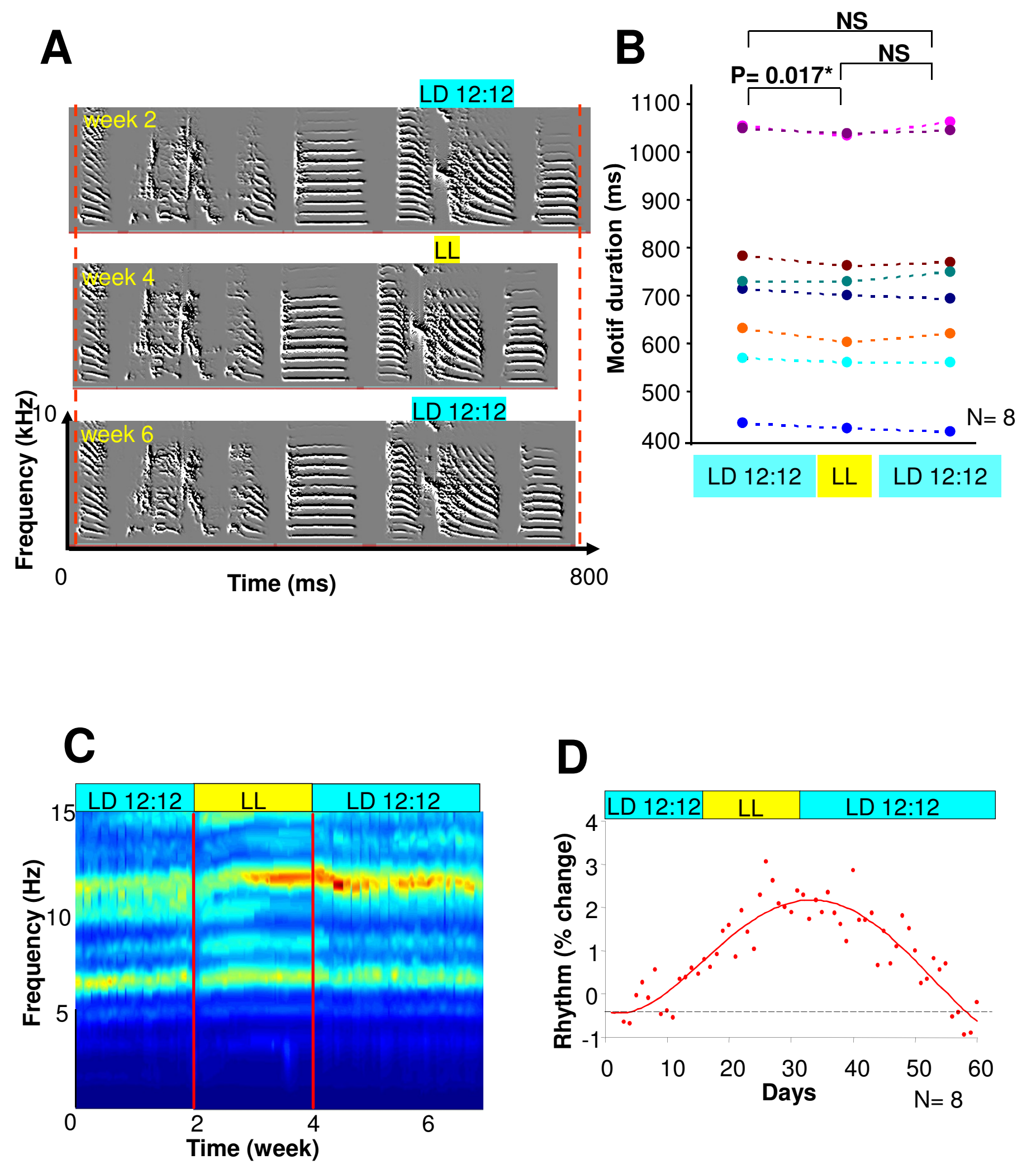

Figure 2 - Derégnaucourt et al. 


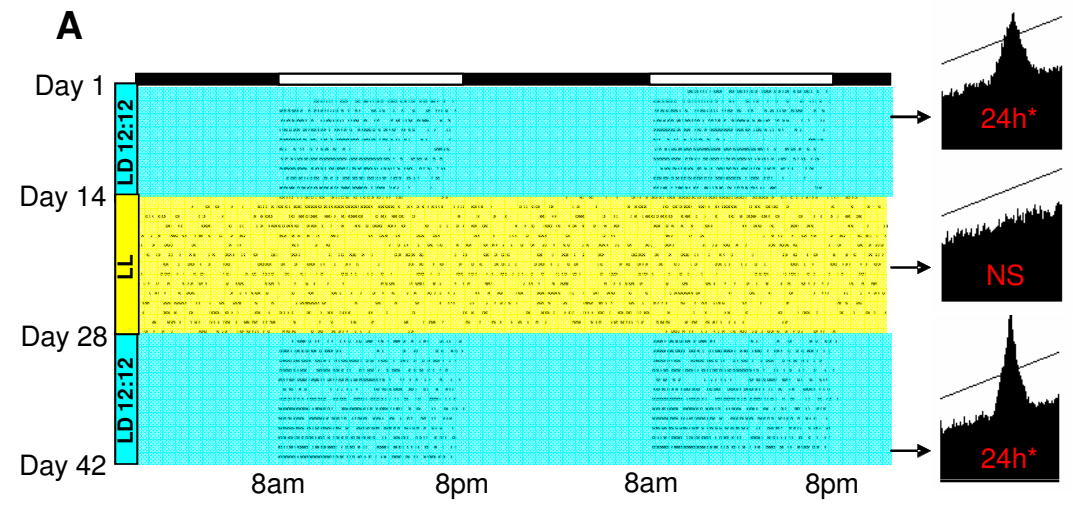

B

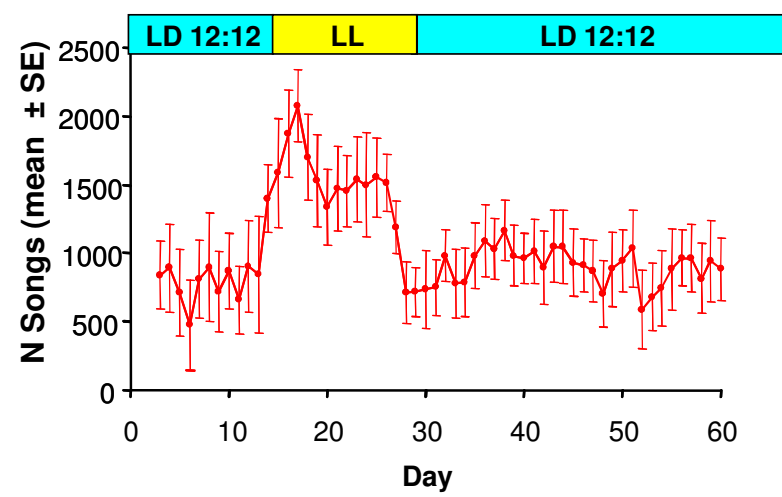

Figure 3 - Derégnaucourt et al. 

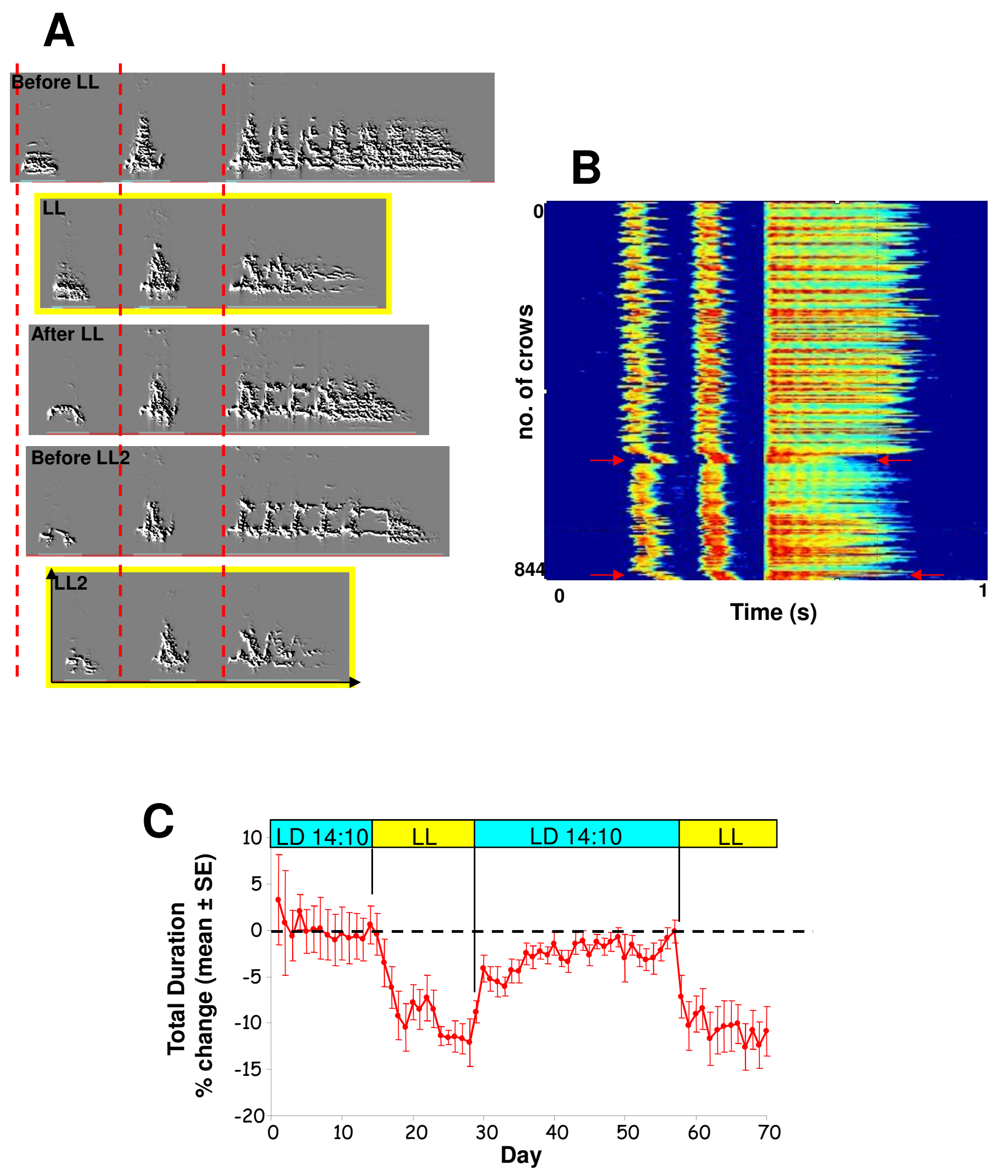

$\mathrm{N}=10$ quails

Figure 4 - Derégnaucourt et al. 


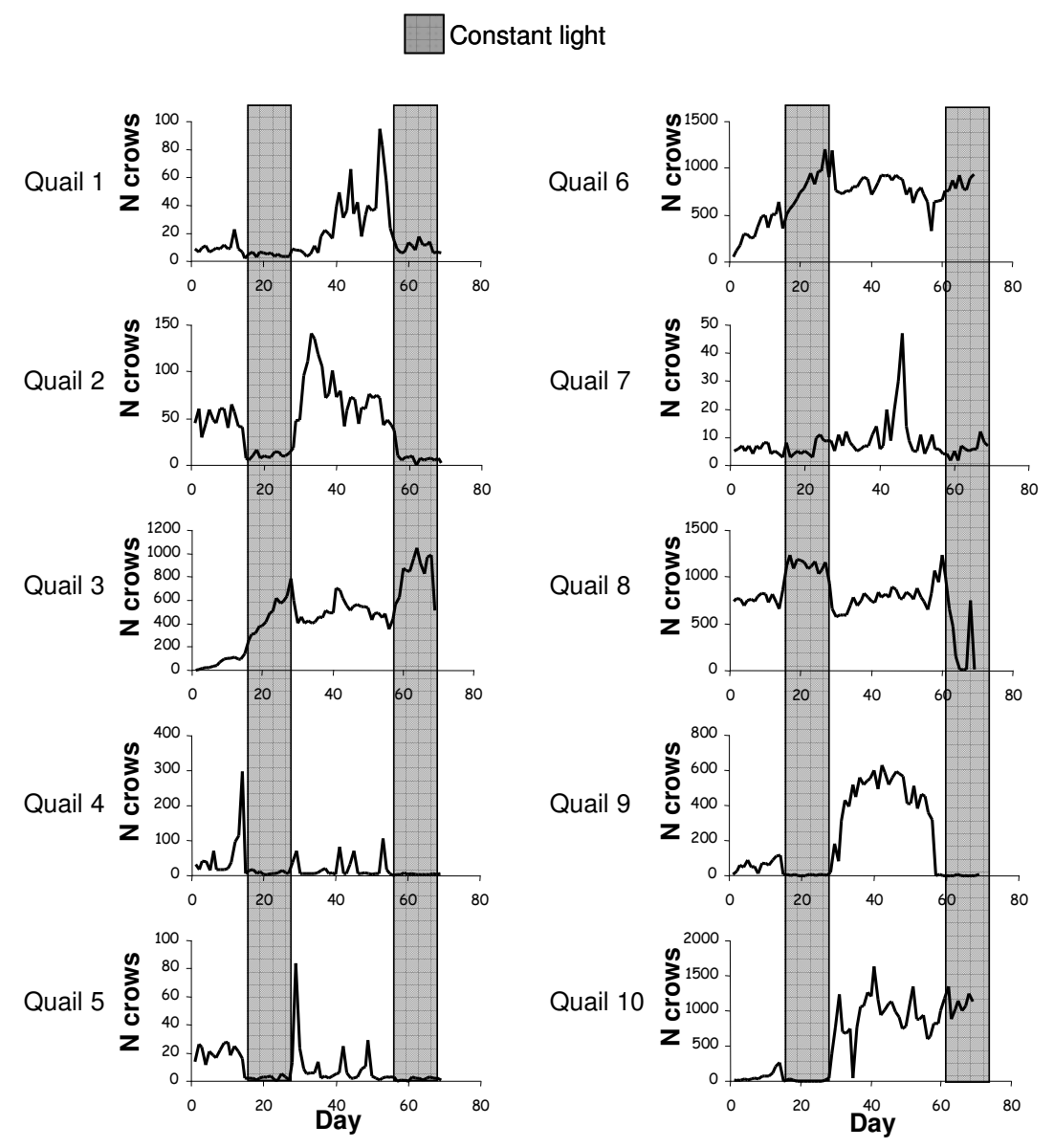

Figure 5 - Derégnaucourt et al. 


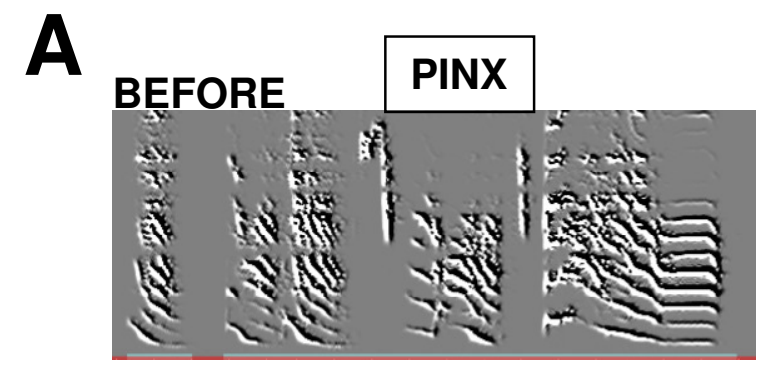

\section{AFTER}
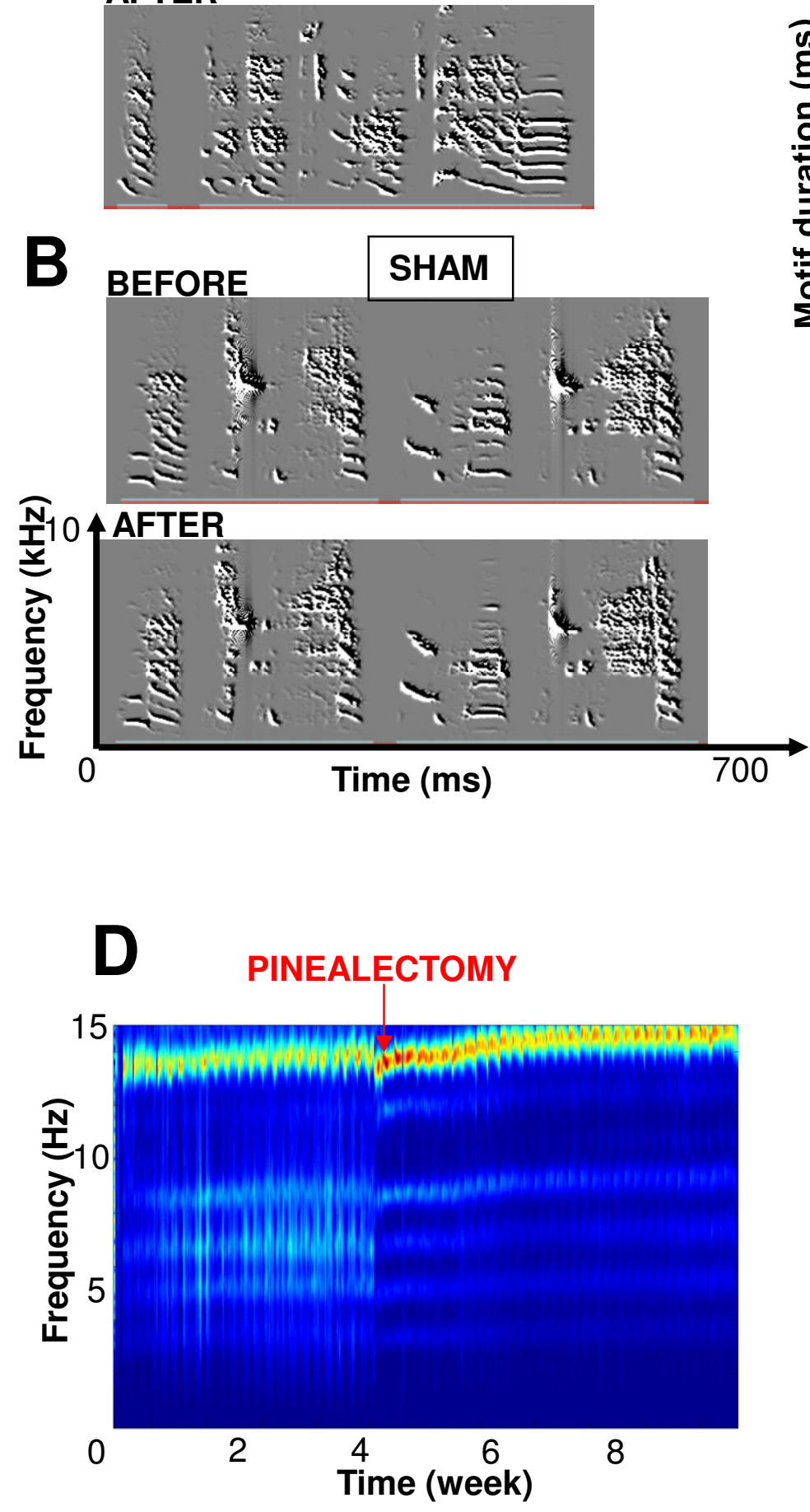
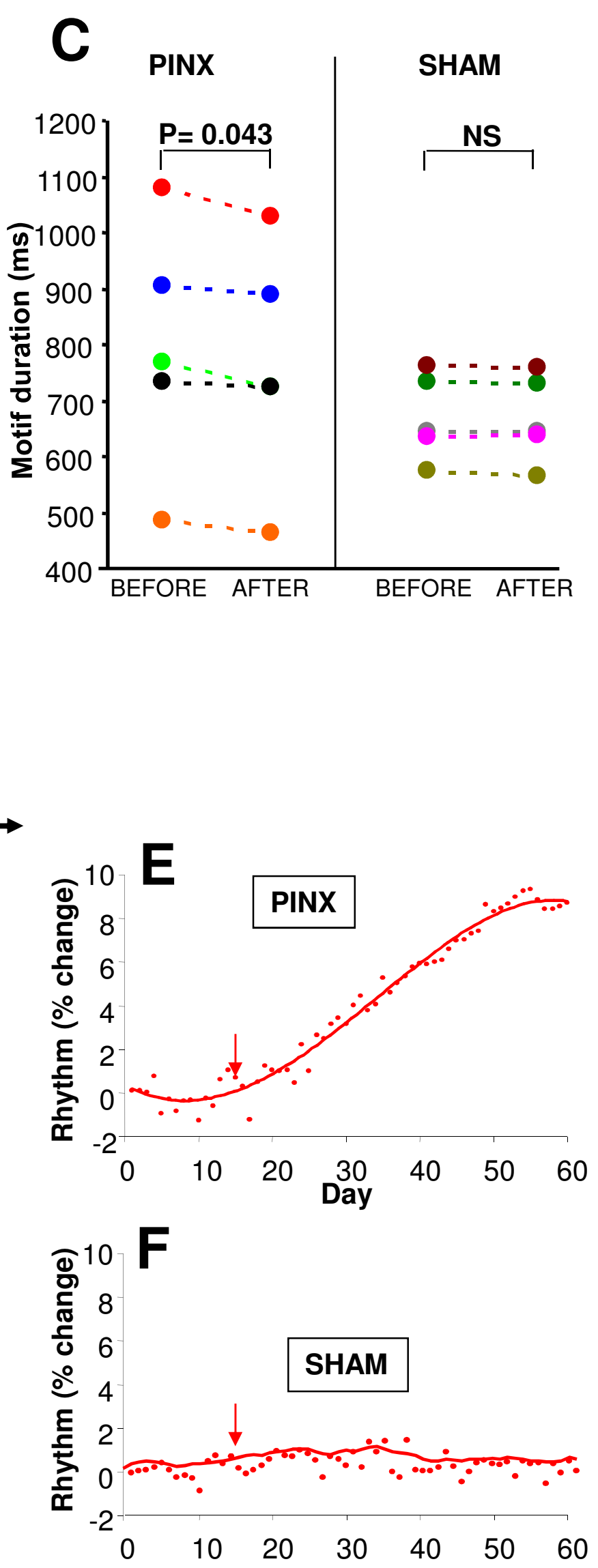

Figure 6 - Derégnaucourt et al. 


\section{PLACEBO}

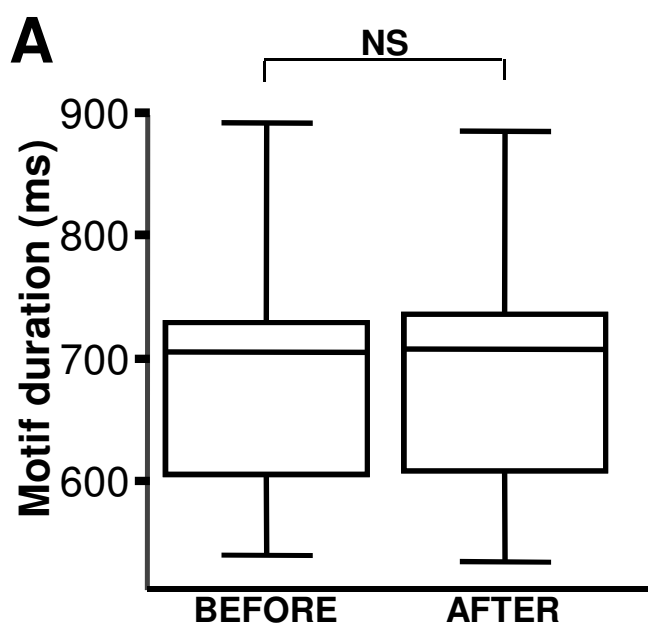

\section{MELATONIN}

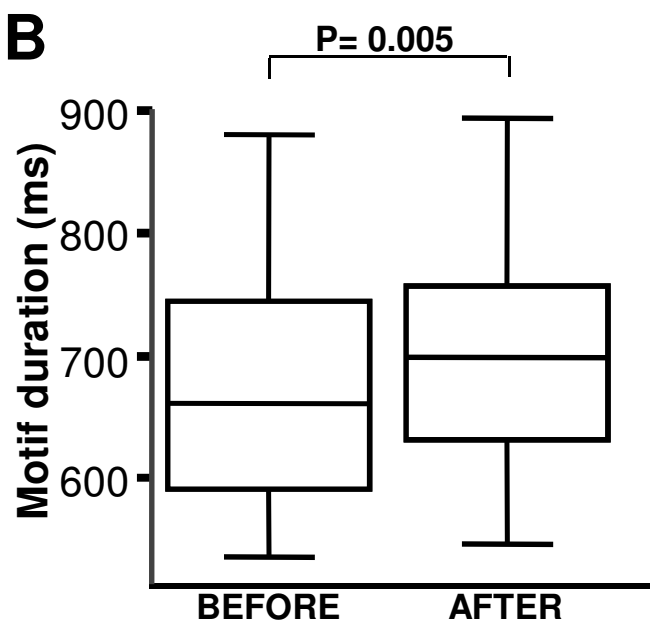

Figure 7 - Derégnaucourt et al. 

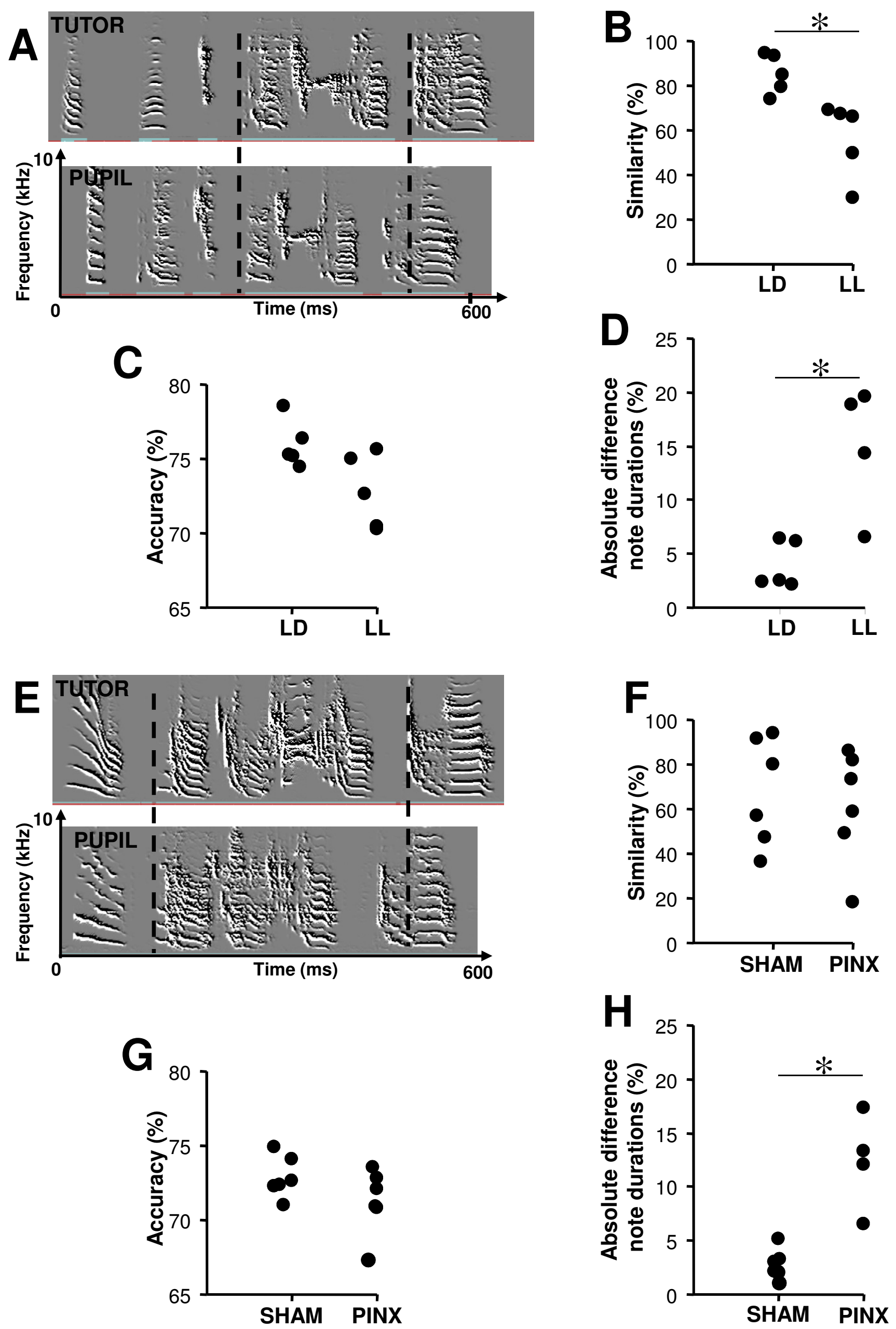

Figure 8 - Derégnaucourt et al. 